Cross-amplification and

\section{Characterization of Microsatellite Loci for the Genus Rhododendron}

\author{
Xue-qin Wang
}

Key Laboratory of Biodiversity and Biogeography, Kunming Institute of Botany, Chinese Academy of Sciences, Kunming 650204, Yunnan, China; and the Graduate School, Chinese Academy of Sciences, Beijing 100049, China

Yuan Huang

Key Laboratory of Biodiversity and Biogeography, Kunming Institute of Botany, Chinese Academy of Sciences, Kunming 650204, Yunnan, China

\section{Chun-lin Long ${ }^{1}$}

Key Laboratory of Biodiversity and Biogeography, Kunming Institute of Botany, Chinese Academy of Sciences, Kunming 650204, Yunnan, China; and the College of Life and Environmental Sciences, Minzu University of China, Beijing 100081, China

Additional index words. Rhododendron, microsatellite loci, cross-amplification

\begin{abstract}
To assess cross-species amplification, we tested 38 microsatellite loci previously developed for Rhododendron delavayi Franch. and $R$. decorum Franch. in eight species representative of the genus $\boldsymbol{R}$ hododendron. Sixteen pairs can be amplified successfully in all species, whereas two failed amplification in all species. Nine loci were polymorphic across six examined species with one to 11 alleles per locus. The observed and expected heterozygosity per locus varied from 0.07 to 0.65 and 0.44 to 0.81 , respectively. Crossapplication of these microsatellite loci will provide a potentially useful tool to investigate the genetic structure, gene flow, and evolutionary relationships in genus Rhododendron.
\end{abstract}

The genus Rhododendron includes widely distributed flowering plants found throughout the world with the exception of Africa and South America and contains over 1000 species (Chamberlain et al., 1996). Centers with highest diversity and endemism of the genus are the Himalayas and Malaysia (Fang and Min, 1995; Sleumer, 1966). There are 571 species distributed in China, of which 409 species are endemic (Fang et al., 2005). Many Rhododendron species are particularly valued for horticulture because of their large and impressive flowers (Sleumer, 1949). Rhododendron's high diversity and wide geographical range have made it an important genus for fundamental and applied research and biodiversity conservation. However, there was considerable morphological over-

Received for publication 10 May 2010. Accepted for publication 29 June 2010.

This work was supported by the Ministry of Education of China (B08044 and MUC-985), the Ministry of Science and Technology of China (2008FY110400-2-2 and 2005DK21006), and the Japan Society for the Promotion of Science (JSPS/AP/109080).

We thank Mr. Wang Nian for providing primers and samples and also thank Mr. Yang Jun-bo and Ms. Yang Jing for guidance on experiments. We are grateful to Alex Weiss for his help in editing the English.

${ }^{1}$ To whom reprint requests should be addressed; e-mail long@mail.kib.ac.cn. lap between the species making discrimination problematic, and more than 1000 horticultural hybrids in existence (Bean, 1976) showed the weakness of genetic barriers toward hybridization in this genus.

Microsatellites are repeating sequences of one to six nucleotides that typically exhibit high levels of polymorphism and are randomly dispersed in the genomes of all prokaryotes and eucaryotes (Litt and Luty, 1989; Tautz, 1989). It is important to determine the extent to which a set of simple sequence repeat (SSR) primers can be used across species within a time-consuming de novo microsatellites isolation. Several studies have been conducted on the use of newly developed primers for crossspecific amplification on related species (Lemes et al., 2007; Nevill et al., 2008; Pinheiro et al., 2009).

A dozen pairs of microsatellite primers (Dendauw et al., 2001; Naito et al., 1998; Tan et al., 2009; Wang et al., 2009) were developed for Rhododendron but have not been screened against other members in the genus. There were many previous studies that suggested microsatellite loci could be a useful tool to study hybridization (Duputie et al., 2007; Schrey et al., 2007; Zhang et al., 1994). We report the ability of these markers to amplify SSR loci in closely related taxa with the goal of identifying a set of polymorphic markers that can be used to investigate the genetic structure and diversity, assess the degree of genetic given genus as a result of the expensive and introgression, and determine the parentage of suspected hybrid individuals for species of this genus.

Total genomic DNA was extracted from leaf tissues using the cetyltrimethyl ammonium bromide method (Milligan, 1992). We tested two sets of microsatellite markers previously developed from Rhododendron delavayi Franch. (14 loci) and $R$. decorum Franch. (24 loci). A total of 38 primer pairs were initially screened in eight species representative of the genus Rhododendron using two individuals from each species (Table 1). Polymerase chain reaction (PCR) was done in a $20 \mu \mathrm{L}$ volume using a PTC0200 thermal cycler (MJ Research, Ashland, OR). Each reaction was performed using $20 \mathrm{ng}$ DNA, $1 \mu \mathrm{M}$ of each dNTP, $1 \mu \mathrm{M}$ each primer, $1 \times$ Taq buffer, and $1 \mathrm{U}$ of Taq polymerase (TaKaRa). Amplifications were carried out according to the following protocol: initial denaturing step at $95^{\circ} \mathrm{C}$ for $5 \mathrm{~min}, 30$ cycles of $94^{\circ} \mathrm{C}$ for $30 \mathrm{~s}$, annealing temperature $\left({ }^{\circ} \mathrm{C}\right)$ for each locus/ species for $30 \mathrm{~s}, 72{ }^{\circ} \mathrm{C}$ for $30 \mathrm{~s}$, and a final extension step at $72{ }^{\circ} \mathrm{C}$ for $8 \mathrm{~min}$. The products were electrophoresed in $1.5 \%$ agarose gel and sized with a 1-kb DNA ladder (Fermentas, Ontario, Canada). After PCR optimization, the loci that showed clear and robust band amplification were selected for further analysis of polymorphisms.

We focused our effort on six species belonging to different sections of the genus Rhododendron (Fang et al., 2005): R. irroratum Franch. (Sect. Ponticum G. Don), R. molle (Blume) G. Don (Sect. Pentanthera G. Don), $R$. simsii Planchon (Sect. Tsutsusi Sweet), $R$. pachypodum I. B. Balfour \& W. W. Smith (Sect. Rhododendron), R. spiciferum Franch. (Sect. Trachyrhodion Sleumer), and R. fuyuanesis Z. H. Yang (Sect. Rhodobotrys Sleumer). $R$. irroratum and $R$. pachypodum were natural populations located in Yangbi County and Fuming County (Yunnan, China), respectively. Other species were cultivated populations from Kunming Botanical Garden (Yunnan, China). Leaves of 10 random plants were sampled from each population. The PCR products were stored at $4{ }^{\circ} \mathrm{C}$ until analysis using the automated capillary electrophoresis QIAxcel system (Qiagen, Hilden, Germany), which uses a preassembled cartridge (cartridge type Qiaxcel DNA high-resolution cartridge) to simultaneously run samples and collect data. The PCR samples were automatically loaded into an individual capillary and voltage was applied. A detector in the instrument detected the nucleic acid molecules as they migrated toward the positively charged terminus of the capillary. These data were passed through a photomultiplier before being converted to an electropherogram and gel image. To enable accurate size measurements, a QX Alignment Marker (15/500 bp) and a QX DNA Size Marker (25 to $450 \mathrm{bp}$ ) were added to the analysis (Fig. 1). Data were analyzed on a PC running BioCalculator software according to the manufacturer's instructions (Qiagen, Hilden, Germany).

Among the 38 primer pairs tested, 16 pairs were amplified successfully in all species, 
Table 1. Cross-species amplification of 38 microsatellite loci tested for eight related Rhododendron species.

\begin{tabular}{|c|c|c|c|c|c|c|c|c|}
\hline Locus (species) & R. irroratum & R. agastum & R. araiophyllum & R. molle & R. simsii & R. pachypodum & R. spiciferum & R. fuyuanesis \\
\hline RDW1 & + & + & + & + & + & + & + & + \\
\hline RDW4 & + & - & + & - & + & - & + & + \\
\hline RDW6 & + & + & + & + & - & + & + & + \\
\hline RDW11 & + & + & + & + & + & + & + & + \\
\hline RDW13 & + & - & - & - & - & - & + & + \\
\hline RDW14 & + & + & + & + & + & + & + & + \\
\hline RDW17 & + & + & + & + & + & + & + & + \\
\hline RDW18 & - & - & - & - & - & - & - & - \\
\hline RDW22 & + & + & + & - & - & - & - & + \\
\hline RDW27 & - & + & + & + & + & + & + & + \\
\hline RDW31 & + & + & + & + & + & + & + & + \\
\hline RDW33 & + & + & + & + & + & + & + & + \\
\hline RDW34 & - & - & - & - & - & - & - & + \\
\hline RDW46 & + & + & + & + & + & + & + & + \\
\hline RDW51 & + & + & + & + & - & - & + & + \\
\hline R 111 & - & + & + & - & - & - & + & - \\
\hline R 140 & - & + & + & - & - & - & - & - \\
\hline R 147 & - & - & - & + & + & - & - & - \\
\hline R 163 & + & - & + & + & + & + & + & + \\
\hline R 166 & + & + & + & + & + & - & - & + \\
\hline R 172 & + & + & + & - & + & - & - & + \\
\hline R 210 & - & - & - & - & - & - & - & + \\
\hline R 299 & - & - & + & + & - & + & + & + \\
\hline R 318 & - & + & + & - & - & - & + & + \\
\hline R 320 & + & + & + & + & + & + & + & + \\
\hline R 335 & - & + & + & + & + & - & + & + \\
\hline
\end{tabular}

$+=$ successful; $-=$ unsuccessful amplification.

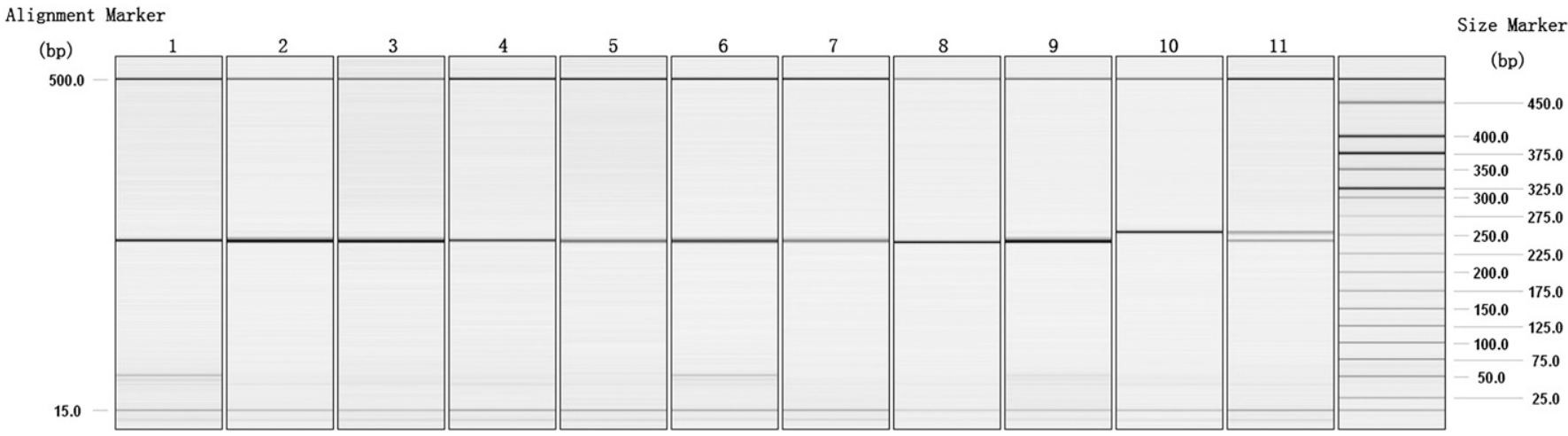

Fig. 1. Example of sizing of alleles in this study. All samples were amplified with primer RDW16: lanes 1 to 5 were samples of $R$. spiciferum and lanes 6 to 11 were samples of $R$. fuyuanesis. A DNA size marker (25 to $450 \mathrm{bp})$ and an alignment marker (15/500 bp) were used to size the different alleles.

whereas two failed amplification in all species (Table 1). Of the 38 loci, 28 (73\%) gave consistent cross-amplification in $R$. irroratum, $29(76 \%)$ in $R$. agastum I. B. Balfour \& W. W. Smith, $30(79 \%)$ in $R$. araiophyllum I. B. Balfour \& W. W. Smith, $27(71 \%)$ in $R$. molle, $26(68 \%)$ in $R$. simsii, $21(55 \%)$ in R. pachypodum, 27 (71\%) in R. spiciferum, and $34(89 \%)$ in R. fuyuanesis (Table 1). Our results did not reveal significant differences in the transferability of all the microsatellites among the eight species. This is likely the result of the high conservation of the primer binding sites in the coding regions assayed in the present study.

A total of nine microsatellite exhibited ideal features for using as codominant molecular markers for further studies in the six examined species (Table 2). The number of alleles per locus, observed $\left(\mathrm{H}_{\mathrm{O}}\right)$ and expected heterozygosity $\left(\mathrm{H}_{\mathrm{E}}\right)$, and deviation from HardyWeinberg equilibrium (HWE) were assessed using GENEPOP Version 3.4 (http://wbiomed. curtin.edu.au/genepop/) (Raymond and Rousset, 1995). The number of alleles per locus ranged from one to 11 (overall mean 4.53 alleles).
Natural populations had more average alleles than cultivated populations. The average alleles of $R$. irroratum and $R$. pachypodum were 6.00 and 5.11, respectively, followed by $R$. fuyuanesis (4.89), R. spiciferum (4.78), R. simsii (3. 44 ), and $R$. molle (2.89). Two loci (RDW31 and RDW38) in R. molle and two loci (RDW46 and $\mathrm{R} 557$ ) in $R$. simsii were monomorphic (Table 3 ). The percentage of polymorphic loci in the six Rhododendron species ranged from $78 \%$ to $100 \%$ with an average of $93 \%$. The observed and expected heterozygosities $\left(\mathrm{H}_{\mathrm{O}}\right.$ and $\left.\mathrm{H}_{\mathrm{E}}\right)$ ranged from 0.07 to 0.65 and 0.44 to 0.81 
Table 2. Characteristics of nine polymorphic microsatellite loci for Rhododendron species.

\begin{tabular}{|c|c|c|c|c|}
\hline Locus & Repeat motif & Primer sequence $\left(5^{\prime}-3^{\prime}\right)$ & Size range (bp) & GeneBank accession no. \\
\hline RDW16 & $(\mathrm{GA})_{9}$ & $\begin{array}{l}\text { R CACCAAGCATCATGCCTCTA } \\
\text { F GGTGATCGTGTCGGAATACA }\end{array}$ & $249-255$ & FJ903460 \\
\hline RDW35 & $\begin{array}{l}(\mathrm{TC})_{5}(\mathrm{CT})_{6} \\
(\mathrm{ATA})_{3}\end{array}$ & $\begin{array}{l}\text { R GTGACTTCGGATTCGTGGAG } \\
\text { F TAAGGTTGGTGTAGCGTGTA }\end{array}$ & $210-219$ & FJ903468 \\
\hline RDW46 & $(\mathrm{CTT})_{3}(\mathrm{GA})_{11}$ & $\begin{array}{l}\text { R AGCAAGATAGAAACTCTGTAAC } \\
\text { F TCTCCAGAAGTACGCAAAT }\end{array}$ & $303-312$ & FJ903473 \\
\hline R-432 & $(\mathrm{CT})_{14}$ & $\begin{array}{l}\text { R CTGGTCCATTCTCCAAGTA } \\
\text { F CCGTTTGAGTATCTTCCC }\end{array}$ & $128-147$ & GU338307 \\
\hline R-544 & $(\mathrm{CT})_{6}$ & $\begin{array}{l}\text { R AATGGAGTAAATGGGGTG } \\
\text { F TCTGGACTTCAAGCAACA }\end{array}$ & $144-170$ & GU338308 \\
\hline R-557 & $(\mathrm{CT})_{9}(\mathrm{TG})_{6}$ & $\begin{array}{l}\text { R TTCCGAACTCCTTCACCAG } \\
\text { F CGAAACTCAGAACCTCCG }\end{array}$ & $204-245$ & GU338309 \\
\hline
\end{tabular}

Table 3. Genetic parameters for the microsatellite loci transferred to six Rhododendron species.

\begin{tabular}{|c|c|c|c|c|c|c|c|c|c|c|c|c|c|c|c|}
\hline \multirow[b]{2}{*}{ Locus } & \multicolumn{5}{|c|}{ R. irroratum } & \multicolumn{5}{|c|}{ R. molle } & \multicolumn{5}{|c|}{ R. simsii } \\
\hline & Size range (bp) & A & $T_{m}\left({ }^{\circ} \mathrm{C}\right)$ & $\mathrm{H}_{\mathrm{E}}$ & $\mathrm{H}_{\mathrm{O}}$ & Size range (bp) & A & $T_{m}\left({ }^{\circ} \mathrm{C}\right)$ & $\mathrm{H}_{\mathrm{E}}$ & $\mathrm{H}_{\mathrm{O}}$ & Size range (bp) & A & $T_{m}\left({ }^{\circ} \mathrm{C}\right)$ & $\mathrm{H}_{\mathrm{E}}$ & $\mathrm{H}_{\mathrm{O}}$ \\
\hline$\overline{\text { RDW1 }}$ & $237-243$ & 3 & 60 & 0.35 & 0.40 & $241-243$ & 2 & 60 & 0.34 & $0.00^{*}$ & $233-252$ & 3 & 60 & 0.63 & 0.90 \\
\hline RDW16 & $248-254$ & 3 & 56 & 0.59 & 0.40 & $249-251$ & 2 & 56 & 0.19 & 0.00 & $240-261$ & 5 & 56 & 0.70 & 0.90 \\
\hline RDW31 & $234-242$ & 4 & 56 & 0.63 & 0.50 & 239 & 1 & 56 & - & - & $230-248$ & 4 & 56 & 0.77 & 0.90 \\
\hline RDW35 & $200-221$ & 8 & 56 & 0.85 & 0.80 & $207-226$ & 7 & 56 & 0.76 & 0.50 & $216-229$ & 4 & 56 & 0.70 & $0.10^{*}$ \\
\hline RDW38 & $126-140$ & 5 & 60 & 0.62 & 0.60 & 138 & 1 & 60 & - & - & $126-136$ & 3 & 60 & 0.53 & 0.50 \\
\hline RDW46 & $269-343$ & 11 & 60 & 0.82 & $0.50^{*}$ & $274-286$ & 3 & 60 & 0.63 & 0.90 & 268 & 1 & 60 & - & - \\
\hline R432 & $113-133$ & 9 & 50 & 0.83 & 0.70 & $112-126$ & 4 & 50 & 0.61 & 0.40 & $111-153$ & 7 & 50 & 0.81 & 0.90 \\
\hline R544 & $149-155$ & 4 & 60 & 0.63 & $0.20 *$ & $154-160$ & 4 & 60 & 0.66 & $1.00 *$ & $148-152$ & 3 & 60 & 0.49 & $0.00 *$ \\
\hline \multirow[t]{2}{*}{ R557 } & $210-226$ & 7 & 50 & 0.70 & $0.10^{*}$ & $204-206$ & 2 & 50 & 0.44 & $0.00^{*}$ & 197 & 1 & 50 & - & - \\
\hline & \multicolumn{5}{|c|}{ R. pachypodum } & \multicolumn{5}{|c|}{ R. spiciferum } & \multicolumn{5}{|c|}{ R. fuyuanesis } \\
\hline Locus & Size range $(b p)$ & A & $T_{m}\left({ }^{\circ} \mathrm{C}\right)$ & $\mathrm{H}_{\mathrm{E}}$ & $\mathrm{H}_{\mathrm{O}}$ & Size range (bp) & A & $T_{m}\left({ }^{\circ} \mathrm{C}\right)$ & $\mathrm{H}_{\mathrm{E}}$ & $\mathrm{H}_{\mathrm{O}}$ & Size range (bp) & A & $T_{m}\left({ }^{\circ} \mathrm{C}\right)$ & $\mathrm{H}_{\mathrm{E}}$ & $\mathrm{H}_{\mathrm{O}}$ \\
\hline$\overline{\text { RDW1 }}$ & $235-237$ & 2 & 60 & 0.27 & 0.10 & $237-245$ & 4 & 60 & 0.74 & $0.40^{*}$ & $237-244$ & 3 & 60 & 0.36 & $0.20^{*}$ \\
\hline RDW16 & $243-249$ & 4 & 56 & 0.66 & $0.20^{*}$ & $244-256$ & 5 & 57 & 0.81 & $0.60 *$ & $245-252$ & 3 & 57 & 0.28 & 0.20 \\
\hline RDW31 & $233-235$ & 2 & 56 & 0.51 & $0.00 *$ & $236-242$ & 2 & 56 & 0.52 & 0.50 & $235-243$ & 4 & 56 & 0.62 & 0.20 \\
\hline RDW35 & $198-222$ & 7 & 56 & 0.78 & 0.50 & $202-228$ & 9 & 56 & 0.91 & 1.00 & $203-230$ & 8 & 56 & 0.85 & 1.00 \\
\hline RDW38 & $118-139$ & 3 & 60 & 0.59 & 0.80 & $126-134$ & 4 & 60 & 0.78 & $0.30 *$ & $123-134$ & 6 & 60 & 0.82 & 0.60 \\
\hline RDW46 & $274-322$ & 9 & 60 & 0.90 & $0.40^{*}$ & $262-272$ & 3 & 60 & 0.53 & 0.30 & $223-275$ & 4 & 60 & 0.65 & $0.30 *$ \\
\hline R432 & $105-132$ & 11 & 50 & 0.84 & 0.70 & $110-145$ & 8 & 52 & 0.80 & $0.50^{*}$ & $117-141$ & 9 & 50 & 0.73 & 0.60 \\
\hline R544 & $149-153$ & 3 & 60 & 0.68 & 0.80 & $148-154$ & 4 & 62 & 0.47 & 0.50 & $151-172$ & 4 & 62 & 0.70 & 0.70 \\
\hline R557 & $190-200$ & 5 & 50 & 0.58 & $0.30 *$ & $199-222$ & 4 & 51 & 0.40 & $0.00 *$ & $197-201$ & 3 & 51 & 0.51 & $0.00 *$ \\
\hline
\end{tabular}

$\mathrm{A}=$ number of alleles; $T_{m}=$ annealing temperature of primer pair; $\mathrm{H}_{\mathrm{E}}=$ expected heterozygosity; $\mathrm{H}_{\mathrm{o}}=$ observed heterozygosity. Statistically significant deviation from Hardy-Weinberg expectation is indicated by the asterisk $(P<0.01)$.

(averages of 0.59 and 0.42 , respectively) (Table $3)$. Among the nine microsatellite screened on six species, $20(37 \%)$ showed significant deviation from HWE $(P<0.01$; Table 3$)$, probably as a result of deficiency of heterozygote or the limitation of sample size. Tests for linkage disequilibrium were run in FSTAT Version 2.9. 3.2 (Goudet, 1995). Significance levels were adjusted using sequential Bonferroni corrections (Rice, 1989). No loci showed significant linkage disequilibrium after Bonferroni correction. The size range of amplification products were similar to those found in species for which the primers were originally developed except for one primer pairs RDW46 (Tables 2 and 3).

In this study, we have demonstrated successful cross-species amplification of nine microsatellite loci among species of the genus Rhododendron. The markers tested here should be of potential use in future studies of genetic diversity, population structure, hybridization, and molecular breeding of species in this genus.

\section{Literature Cited}

Bean, N.H. 1976. Trees and shrubs hardy in the British Isles III (NRh). 8th Ed. John Murry, London, UK.

Chamberlain, D.F., R. Hyam, G. Argent, G. Fairweather, and K.S. Walter. 1996. The genus Rhododendron, its classification and synonymy. Alden Press, Oxford, UK. p. 181.

Dendauw, J., J. De Riek, P. Arens, E. Van Bockstaele, B. Vosman, and M. De Loose. 2001. Development of sequenced tagged microsatellite site (STMS) markers in azalea. Acta Hort. 546:193-197.

Duputie, A., P. David, C. Debain, and D. McKey. 2007. Natural hybridization between a clonally propagated crop, cassava (Manihot esculenta Crantz) and a wild relative in French Guiana. Mol. Ecol. 16:3025-3038.

Fang, M.Y., R.Z. Fang, M.Y. He, L.Z. Hu, H.B. Yang, H.N. Qin, T.L. Min, F. David, P.S. Chamberlain, G.D. Wallace, and A. Anderberg. 2005. Rhododendron (Ericaceae), p. 333. In: $\mathrm{Wu}$, Z.Y. and P.H. Raven (eds.). Flora of China. Vol. 14. Science Press and Missouri
Botanical Garden Press, Beijing, China, and St. Louis, MO.

Fang, R.Z. and T.L. Min. 1995. The floristic study on the genus Rhododendron. Acta Botanica Yunnanica 17:359-379.

Goudet, J. 1995. FSTAT (Version 1.2): A computer program to calculate F-statistics. J. Hered. 86: 485-486.

Lemes, M.R., T.M. Martiniano, V.M. Reis, C.P. Faria, and R. Gribel. 2007. Cross-amplification and characterization of microsatellite loci for three species of Theobroma (Sterculiaceae) from the Brazilian Amazon. Genet. Resources Crop Evol. 54:1653-1657.

Litt, M. and J.A. Luty. 1989. A hypervariable microsatellite revealed by in vitro amplification of a dinucleotide repeat within the cardiac muscle action gene. Am. J. Hum. Genet. 44:397401.

Milligan, B. 1992. Plant DNA isolation. A practical approach, p. 59-88. In: Hoelzel, A.R. (ed.). Molecular genetic analysis of populations. IRL Press, Oxford, UK

Naito, K., Y. Isagi, and N. Nakagoshi. 1998. Isolation and characterization of microsatellites 
of Rhododendron metternichii Sieb. et Zucc. var. hondoense Nakai. Mol. Ecol. 7:927-928.

Nevill, P.G., A. Reed, G. Bossinger, R.E. Vaillancourt, M. Larcombe, and P.K. Ades. 2008. Cross-species amplification of Eucalyptus microsatellite loci. Mol. Ecol. Resour. 8: 1277-1280.

Pinheiro, F., C. Palma-Silva, F. de Barros, and S. Cozzolino. 2009. Cross- amplification and characterization of microsatellite loci for the neotropical orchid genus Epidendrum. Genet. Mol. Biol. 32:337-339.

Raymond, M. and F. Rousset. 1995. GENEPOP version 1.2: Population genetics software for exact tests and ecumenicism. J. Hered. 86:248249.
Rice, W.R. 1989. Analyzing tables of statistical tests. Evolution 43:223-225.

Schrey, A.W., B.L. Sloss, R.J. Sheehan, R.C. Heidinger, and E.J. Heist. 2007. Genetic discrimination of middle Mississippi River Scaphirhynchus sturgeon into pallid, shovelnose, and putative hybrids with multiple microsatellite loci. Conserv. Genet. 8:683693.

Sleumer, H. 1949. A system of the genus Rhododendron L. Bot. Jahrb. Syst. 74:511-553.

Sleumer, H. 1966. An account of Rhododendron in Malesia. Flora Malesiana: Ser. 1:474-668.

Tan, X.X., Y. Li, and X.J. Ge. 2009. Development and characterization of eight polymorphic microsatellites for Rhododendron simsii
Planch (Ericaceae). Conserv. Genet. 10:15531555.

Tautz, D. 1989. Hypervariability of simple sequences as a general source for polymorphic DNA markers. Nucleic Acids Res. 17:64636471.

Wang, X.Q., Y. Huang, and C.L. Long. 2009. Isolation and characterization of twenty-four microsatellite loci for Rhododendron decorum Franch. (Ericaceae). HortScience 44:20282030.

Zhang, Q.F., Y.J. Gao, S.H. Yang, R.A. Ragab, M.A.S. Maroof, and Z.B. Li. 1994. A diallel analysis of heterosis in elite hybrid rice based on RFLPs and microsatellites. Theor. Appl. Genet. 89:185-192. 